\title{
UTILIDAD DEL ARTE, FUNCIÓN DE LA LITERATURA Y PENSAMIENTO NARRATIVO
}

\section{THE USEFULNESS OF ART, THE FUNCTION OF LITERATURE AND THE NARRATIVE THOUGHT}

Javier Rubiera Université de Montréal

\section{ABSTRACT}

This article considers, in the first place, the way of asking about the function of literature and its value as a form of knowledge in some texts of literary critics (Wellek and Warren), university professors (Mustapha Fahmi and Raúl Álvarez Moreno) or current novelists (Javier Cercas, Juan Villoro and Juan Gabriel Vásquez). In the second part, Rafael Núñez Ramos' theory on narrative thought and the cognitive aspects of narrative is analyzed. In the third part, the author shows how this theory by Núñez Ramos illuminates the experience of reading the Christian stories of the Japanese writer R. Akutagawa, recently co-translated into Spanish by the author.

Key words: Cognitive aspects of narrative. Fiction. Stoytelling. Role of Humanities. Núñez Ramos. Akutagawa. 


\section{RESUMEN}

Este artículo considera, en primer lugar, el modo de preguntarse por la función de la literatura y de su valor como forma de conocimiento en algunos textos de críticos literarios (Wellek y Warren), profesores universitarios (Mustapha Fahmi y Raúl Álvarez Moreno) o novelistas actuales (Javier Cercas, Juan Villoro y Juan Gabriel Vásquez). En la segunda parte, se analiza la teoría literaria de Rafael Núñez Ramos en torno al pensamiento narrativo y a los aspectos cognitivos del relato. En la tercera parte, el autor muestra de qué modo esta teoría de Núñez Ramos ilumina la propia experiencia de lectura de los relatos cristianos del escritor japonés R. Akutagawa, recientemente co-traducidos al español por el autor.

Palabras clave: Aspectos cognitivos del relato. Ficción. Narración. Función de las Humanidades. Núñez Ramos. Akutagawa.

Fecha de recepción: 24 de noviembre de 2021.

Fecha de aceptación: 12 de diciembre de 2021.

Cómo citar: Rubiera, Javier (2021): «Utilidad del arte, función de la literatura y pensamiento narrativo», en Actio Nova: Revista de Teoría de la Literatura y Literatura Comparada, 5: 436-457. DOI: https://doi.org/10.15366/actionova2021.5.018 


\section{1.- INTRODUCCIÓN}

Al ofrecer al profesor Rafael Núñez mi contribución en homenaje a su larga trayectoria como teórico de la literatura, este artículo se mueve entre la evocación de tiempos juveniles y la reflexión crítica a partir de algunos de sus textos que han resultado más estimulantes para mi propia labor intelectual. He querido, así, de modo bien consciente, que la redacción en primera persona y el tono íntimo de varios párrafos subrayen que el estímulo del magisterio de Rafael Núñez ha ido mucho más allá de una simple relación académica y se ha teñido con el color de la amistad, en el más noble sentido ciceroniano de la palabra. Por todo ello, en vez de un texto que desarrollara algún concepto teórico en relación con el teatro de los siglos de oro - mi principal campo de investigación—, he preferido ofrecerle estas reflexiones en torno a la función de la literatura y a «la ficción como conocimiento» ${ }^{1}$, que desembocan en un ejemplo concreto y reciente al enfrentarme a la traducción de doce relatos de Akutagawa (1892-1927), uno de los más afamados narradores japoneses del siglo $\mathrm{XX}^{2}$. En el camino, trataré de hacer resaltar la original contribución de Núñez Ramos a la teoría literaria a partir de un examen atento de su obra El pensamiento narrativo (2010).

A principios de los años ochenta del pasado siglo contaba la Universidad de Oviedo con ilustres catedráticos de lengua y de literatura, como Emilio Alarcos Llorach, José Miguel Caso González y José María Martínez Cachero. Al prestigio de la Universidad había contribuido también el que desde finales de 1975 ocupara la cátedra de Gramática general y Crítica literaria María del Carmen Bobes Naves, que había ocupado antes la de Gramática histórica en Santiago de Compostela. Carmen Bobes fue una de las impulsoras de los estudios de Semiología o Semiótica en España ${ }^{3}$, disciplina, enfoque o «ciencia» por la que muchos jóvenes nos sentimos atraídos en aquel tiempo. En el primer año de la carrera de Filología española, algunos grupos de estudiantes no tuvimos como profesora de Crítica literaria a Carmen Bobes, sino a los profesores que la habían acompañado desde Santiago, Alberto Álvarez Sanagustín y Rafael Núñez Ramos. Compartían despacho junto al de doña Carmen, y los estudiantes que frecuentábamos tanto las aulas como la cafetería de la Facultad, en la

\footnotetext{
1 «La ficción como conocimiento» es el título del capítulo 5 de Elpensamiento narrativo (Núñez Ramos, 2010).

${ }^{2}$ Me refiero a El tabaco y el diablo, y otros relatos cristianos, una cotraducción realizada junto con $\mathrm{H}$. Higashitani.

${ }^{3}$ Sobre la trayectoria de la profesora Carmen Bobes véanse el artículo de M. A. Garrido Gallardo y la laudatio de D. Villanueva en el libro en su homenaje (Garrido Gallardo y Frechilla Díaz, 2007: 25-48), así como el reciente trabajo de María del Carmen Bobes Naves (2020) titulado «Los objetos y los modos de la investigación lingüística y literaria. La transversalidad», en Javier García Rodríguez (ed.) (2020): 279-297.
} 
Plaza de Feijoo, acostumbrábamos a verlos juntos. Aunque fuéramos alumnos de uno, también empezamos a relacionarnos con el otro. Ese fue mi caso entre 1983 y 1988, pues siendo Álvarez Sanagustín mi profesor —y posteriormente mi director de memoria de licenciatura y de tesis doctoral-, sobre todo en los dos últimos años de carrera se fue intensificando también mi relación con Rafael Núñez, hasta alcanzar muy estrecha conexión durante mis cuatro años de doctorado (1989-1992), en los que mantuvimos muchas conversaciones sobre cuestiones de filosofía, crítica literaria y música. Recuerdo especialmente nuestros intercambios sobre Sentimiento y forma de Susanne K. Langer, sobre La actualidad de lo bello de Hans-Georg Gadamer o sobre el pensamiento antropológico de Clifford Geertz, a los que tanto debe mi formación, y junto a ellos numerosas afinidades electivas que fueron fortaleciendo nuestra relación académica y amistosa: Roland Barthes, Umberto Eco, Edward T. Hall, Roman Jakobson, Octavio Paz... Muchos años después, tuve la fortuna de poder recibirle como profesor invitado en Université de Montréal, donde escuché las primeras ideas y el esbozo de su libro El pensamiento narrativo. Aspectos cognitivos del relato (2010), al que luego me referiré, tal como en su momento había podido disfrutar con las ideas preliminares de las felices formulaciones de La poesía (1992).

\section{2.- UTILIDAD DEL ARTE Y FUNCIÓN DE LA LITERATURA}

Antes de introducirnos propiamente en cuestiones de semiología, entre los textos básicos de teoría de la literatura que utilizábamos los estudiantes en primer año de la licenciatura, destacaban dos manuales: Teoría literaria de René Wellek y Austin Warren ${ }^{4}$ y el más reciente y completo de Vítor Manuel de Aguiar e Silva Teoría de la literatura. Eran la puerta de entrada a una reflexión crítica y razonada, y en ambos traté de buscar respuesta a una de las preguntas fundamentales que inquietan a un estudiante durante su formación, sobre todo porque otras personas de su entorno se la formulan inevitablemente mientras cursa estudios y también después, si se convierte en profesor: ¿para qué sirve la literatura? Tanto Wellek-Warren como Aguiar e Silva trataban de ello en capítulos titulados respectivamente «Función de la literatura» y, con más matiz a través de un plural, «Funciones de la literatura». En secuencia lógica, tales capítulos iban precedidos de otros que trataban

\footnotetext{
${ }^{4}$ El prólogo a la primera edición en inglés está firmado en 1948.

${ }^{5} \mathrm{El}$ prefacio de la primera edición en portugués es de 1967.
} 
sobre «Naturaleza de la literatura» $\mathrm{O}$ «El concepto de literatura. La teoría literaria» ${ }^{6}$. Las poco más de diez páginas que dedicaban Wellek y Warren a la cuestión proporcionaban ${ }^{7}$, en su enfoque general, la idea de que «la cuestión relativa a la función de la literatura tiene una larga historia, que en el mundo occidental va desde Platón a nuestros días» (1966: 45). Recuerdan que «la historia de la estética casi podría resumirse como una dialéctica en que la tesis y la antítesis son el dulce y el utile de Horacio» (1966: 36), se hacen preguntas como «itiene la literatura función o funciones?» o «¿tiene la literatura una función, una utilidad que ninguna otra cosa cumpla también?» (1966: 38), y sobre todo se detienen a examinar la posibilidad de que en la poesía se dé «una especie de conocimiento» o que el teatro y la novela puedan tener «valores cognoscitivos» (1966: 38-40). Tratan de aclarar, además, lo que consideran que en buena parte es una controversia semántica en torno a lo que puede considerarse «verdad»o «conocimiento» en el arte, para lo que discuten o se apoyan en citas de autores contemporáneos como Eastman, Elliot, Forster, MacLeish o Langer. Como es lógico pensar, Wellek y Warren se refieren también a «las concepciones de la función de la literatura que se arraciman en torno a la voz "catarsis"» (1966: 44), pero en lo que me interesa insistir es en parte del comentario final, ya a modo de resumen, en el que los dos críticos desembocan en una reflexión que no ha perdido actualidad:

La cuestión relativa a la función de la literatura [...] no es una cuestión que el poeta o los que gustan de poesía planteen instintivamente; para uno y otros, «la belleza es su pretexto de ser», como una vez se vio arrastrado a decir Emerson. La cuestión la plantean más bien los utilitaristas y los moralistas, o los hombres de Estado y los filósofos, esto es, los representantes de otros valores particulares o los árbitros especulativos de todos los valores. ¿Cuál es - preguntan- la utilidad de la poesía, cui bono? Y plantean la pregunta en la plena dimensión social o humana. Así provocados, el poeta y el espontáneo lector de poesía se ven obligados, en su calidad de ciudadanos moral o intelectualmente responsables, a dar a la comunidad alguna respuesta razonada. [...] Escribiendo con esta finalidad a la vista y con este público en perspectiva, subrayan más, claro está, la «utilidad» que el «deleite» de la literatura; y de aquí que semánticamente fuera hoy fácil equiparar la «función» de la literatura a sus relaciones extrínsecas (Wellek y Warren, 1966: 45-46).

\footnotetext{
${ }^{6}$ «En todo estudio lógicamente concatenado, la naturaleza y la función de la literatura han de ser correlativas» (Wellek y Warren, 1966: 35). «Después del intento de determinar la naturaleza de la literatura, conviene formular una nueva pregunta: ¿cuál es la finalidad o la función de la literatura?» (Aguiar e Silva, 1981: 43).

${ }^{7}$ Dejo de lado ahora el comentario al largo capítulo (sesenta páginas) de Aguiar e Silva, para no prolongar la introducción y porque las observaciones de Wellek y Warren me permiten llegar directamente al núcleo de la cuestión.
} 
Para el que está dentro de la actividad literaria (el hacedor o poeta), tanto como para el que dedica su vida al estudio, a la crítica y a la enseñanza de la literatura, la pregunta por su utilidad, su sentido o su función no es instintiva, primaria, no la siente como algo inquietante ni problemático. Pero parece inevitable que, desde el medio social y económico al que pertenece, en su condición de ciudadano y contribuyente en la comunidad en la que vive, se cuestione su utilidad (la de la persona y la de su actividad «laboral»). La cuestión puede plantearse en el medio familiar — el padre que pregunta a su hija que para qué estudia una carrera de letras; la madre que se preocupa porque su hijo pasa el día leyendo novelas o escribiendo versos (¿para qué? ¿no pensarás que te vas a ganar la vida con eso?) — hasta el equipo rectoral o la comisión ministerial que se preguntan por el sentido de otorgar partida presupuestaria a determinados programas «inútiles». ¿Quién no se ha visto envuelto en una discusión sobre la utilidad de ciertas carreras y profesiones en un tiempo de crisis y de necesidades primarias sin resolver en una sociedad en acelerada transformación? ¿De qué modo revierte a la sociedad lo que esta ha invertido en la formación de un universitario que se dedica a enseñar literatura? ¿Es, en algún sentido, productivo para la sociedad? ¿Para qué sirve, entonces, la literatura? Etc. Esta cuestión, por lo tanto, se encuentra en el debate público.

En relación con la relevancia de los studia bumanitatis para el mundo actual, hace unos años, Nuccio Ordine (2013) publicó su conocido manifiesto La utilidad de lo inútil en el que proporcionaba claros argumentos y numerosos ejemplos felices, sobre todo muy convincentes para los ya convencidos, pero no sé si tan efectivos sobre los que preguntan por la utilidad de los saberes humanísticos en la sociedad contemporánea creyendo ya conocer otra respuesta bien diferente, quizás porque pertenecen a esos que han «nacido tan cerca de la aturdidora catarata del Nilo que no [pueden] oír la música de las esferas que hay en la poesía» (Sidney, 2003: 192).

Los profesores universitarios se sienten interpelados desde unos presupuestos lógicos de carácter empresarial y responden desde otros presupuestos lógicos diferentes ${ }^{8}$, por lo que es prácticamente imposible un verdadero diálogo, a no ser que lo que se pretenda sea mostrar que no es posible el diálogo desde esos presupuestos utilitaristas.

En la misma línea de pensamiento, no es infrecuente que en la prensa diaria asome la voz y la pluma de un profesor que trata de sensibilizar a la opinión pública (¿está aún la

\footnotetext{
${ }^{8}$ Una clara e importante excepción supone el aporte de las humanidades digitales, que quedan ahora fuera de mi consideración.
} 
opinión pública en los periódicos?) con sus argumentos a partir de la poesía misma ${ }^{9}$. Así hizo en Le Devoir Mustapha Fahmi, profesor de literatura inglesa de la Université de Québec à Chicoutimi con un artículo titulado «De quoi avons-nous besoin?» (2020: B11), donde recordaba el episodio de El rey Lear shakespeariano (acto segundo, escena IV) en el que el Rey se enfrenta a sus hijas —a las que dice haber dado todo-, pues quieren limitarle el número de caballeros de su séquito, porque qué necesidad tiene de tantos:

GONERILA. Escuchad, mi señor: ¿qué necesidad tenéis de que os acompañen veinticinco, ni diez, ni cinco, a una casa donde el personal, dos veces mayor que el vuestro, tiene la orden de serviros?

REGANIA. ¿Qué necesidad tenéis ni de uno?

LEAR. ¡Oh, no hay que razonar sobre la necesidad! Nuestros más viles mendigos son en alguna pobrísima cosa superfluos. No concedáis a la Naturaleza más de lo que ella exige, y la vida del hombre será de tan bajo valor como la de las bestias. Tú eres una dama; si solo para mantenerte en calor te ataviaras con lujosos vestidos, iqué!, la Naturaleza no tendría necesidad de los lujosos vestidos que llevas, que escasamente te dan calor (Shakespeare, 1980: 184-185).

Entre otras valiosas observaciones, Fahmi reconoce que podría ser legítimo ver en la respuesta del rey una apología del consumo y de la extravagancia o una manera de justificar el exceso en el que viven los privilegiados de la sociedad, pero que lo importante en la respuesta de Lear, de alcance más universal, es el cuestionamiento de estas posiciones que se preguntan por la necesidad de una manera tan radical que podrían deshacer a su paso «tout ce que les humains ont érigé de beau ou de transcendant» (Fahmi, 2020: B11).

Se pregunta Fahmi:

Avons-nous besoin, par exemple, de garder ouverts des musées qui coûtent cher à la société et qui n'attirent qu'une partie de la population? Avons-nous besoin d'enseigner les arts, la littérature et la philosophie quand la société a surtout besoin de médecins, d'ingénieurs et d'informaticiens? Le roi Lear n'a pas besoin de 100 chevaliers, et il est le premier à le savoir (Fahmi, 2020: B11).

Y concluye:

Il est faux, à mon sens, de croire que les humains peuvent s'accomplir dans la retenue ou dans l'austérité. Au contraire, c'est en transcendant les limites de nos besoins humains les plus élémentaires que nous parvenons à révéler le meilleur de nous-mêmes. Un monde où les choses sont jugées strictement en fonction

\footnotetext{
${ }^{9}$ Más que volver a evocar ejemplos de la obra de N. Ordine, me ha parecido conveniente ilustrar esta parte introductoria con dos ejemplos que provienen de mi horizonte canadiense y quebequés, muy probablemente desconocidos para el lector, pero bien significativos de la actualidad del problema que tratamos.
} 
des besoins qu'elles peuvent satisfaire est un monde sans monuments, sans art, sans élégance (Fahmi, 2020: B11).

La sensación y el sentimiento de crisis se han agudizado en los tiempos de la pandemia de estos años 2020 y 2021, provocada por el Covid-19. En este contexto es lógico también que se levanten voces desde el medio universitario, tratando de hacer valer la importancia de «the Role of the Humanities During Times of Crisis», como hace el profesor de The University of British Columbia Raúl Álvarez Moreno en el apartado de «Noticias y eventos» del sitio web de su universidad (Álvarez Moreno, 2021) ${ }^{10}$. Frente a una perspectiva materialista neoliberal ${ }^{11}$, defiende Álvarez Moreno el valor de las humanidades, porque «la mayor parte de nuestros problemas no son solamente tecnológicos, ni aun económicos; son problemas humanos. He ahí por qué las humanidades no son solo importantes, sino indispensables». Entre otros argumentos de sumo interés para reforzar su punto de vista como el de la capacidad de las humanidades para resistir la dictadura del beneficio económico- quisiera recordar, por la relación directa con asuntos de este artículo, cómo subraya «the Power of Storytelling», porque «las historias son el mejor modo de aprender sobre nuestras emociones y sus dinámicas — sin ser usados para que nos vendan cosasque tienen impacto muy grande sobre nuestro modo de vida y sobre el modo en que gestionamos las crisis».

Los «storytellers», los narradores, sobre todo los novelistas, participan continuamente en este debate, porque son interpelados muy frecuentemente en relación con la utilidad de la literatura, con la función social de la novela o con el tipo de verdad o conocimiento que se expresa en la ficción narrativa ${ }^{12}$. Tres ejemplos muy recientes confirmarán aquella observación de Wellek y Warren, recogida más arriba, de que «la cuestión relativa a la función de la literatura tiene una larga historia, que en el mundo occidental va

\footnotetext{
${ }^{10} \mathrm{El}$ artículo apareció el 28 de enero de 2021 en la página web del Department of French, Hispanic and Italian Studies, The University of British Columbia.

11 «For many (imbued with neoliberal materialist ideas), the humanities are impractical. Degrees in art, history or philosophy are viewed as expensive luxuries in today's world. For them, we should move to teaching specific, technical skills that lead to profitable jobs, without to much time to think» (Álvarez Moreno, 2021). [«Para muchos (imbuídos de ideas materialistas neoliberales), las humanidades no tienen valor práctico. Títulos en arte, historia o filosofía se ven como lujos caros en el mundo de hoy. Para ellos, deberíamos pasar a enseñar habilidades técnicas, específicas, que lleven a trabajos provechosos, sin mucho tiempo en el que pensar». Traducción mía, como para las otras citas del texto de Álvarez Moreno].

${ }^{12} \mathrm{El}$ valor de sus respuestas depende en buena medida del grado de profundidad en la reflexión que cada autor haya dado a su conciencia de escritor y al modo de concebir y estructurar sus ficciones narrativas. Pienso en casos paradigmáticos de narradores de gran perspicacia teórica y crítica como Francisco Ayala, Gonzalo Torrente Ballester o Mario Vargas Llosa.
} 
desde Platón a nuestros días». Ellos lo escribían hacia 1948, pero es válida para «nuestros días» de 2021, porque, evidentemente, no puede haber respuesta definitiva que encuentre la unanimidad. Un artículo de un escritor español en una revista-suplemento dominical de gran difusión, una entrevista a un famoso creador de ficciones mexicano, una «Nota del autor»al final de la última novela de un narrador colombiano: lugares diversos, bien recientes, como decía, para continuar este diálogo infinito.

Javier Cercas — que tanto ha escrito sobre la verdad y la ficción, la verdad de la ficción, la novela sin ficción, etc.- publica en El País Semanal un artículo que, a pesar de su contundente título («iPara qué sirve el sexo?»), es una reflexión sobre la utilidad de la literatura a partir de la famosa y provocadora cita de Oscar Wilde «Todo arte es completamente inútil». Por un lado, propone Cercas enterrar el «inútil concepto burgués de utilidad»y reconocer la evidencia de que «la literatura es antes que nada un placer, como el sexo, pero también es una forma de conocimiento, como el sexo» $(2021: 74)^{13}$. Por otro lado, Cercas afirma que

si la literatura se toma en serio a sí misma, si el escritor es fiel a sus obsesiones y cumple con su obligación y no tiene miedo y se arriesga a ir hasta el fondo de lo desconocido para encontrar lo nuevo - como escribió un coetáneo de Wilde: Charles Baudelaire-, entonces la literatura no sólo es placer y diversión, que es lo primero que debe ser, sino también purificación y conocimiento y autoconocimiento y rebeldía; igualmente, o sobre todo, una forma de vivir más, de una manera más rica, más compleja y más intensa. ¿Hay algo tan útil como eso?

El pasado 12 de noviembre de 2021, con motivo de la publicación de su última novela (La tierra de la gran promesa), Juan Villoro es entrevistado por Andrés Seoane para el suplemento «El Cultural» del diario El Mundo. A partir del contenido de la novela, es inevitable que la conversación con un escritor hispanoamericano caiga en algún momento sobre la relación de la ficción con la historia y sobre el compromiso moral del artista; casi tan inevitable como que las respuestas hablen de placer y belleza, y del modo en el que la ficción da sentido y ordena la realidad:

P. También reflexiona sobre la responsabilidad moral del artista. Si las novelas, el arte, reconstruyen la historia, algo muy notorio en Latinoamérica, ¿cuál es este papel del creador?

13 Desgraciadamente, Cercas no tiene espacio para explicar en qué sentido el sexo es una forma de conocimiento, o simplemente cree que no hace falta explicarlo. 
R. Cada cual escoge una perspectiva para relacionarse con el mundo que tenemos. A mi juicio hay una doble responsabilidad. Por un lado, el arte es una manera de encontrar armonía y sentido en algo que no lo tiene. La realidad ocurre de manera abusiva, contradictoria, desagradable, y la literatura le puede dar un orden al $\operatorname{caos}^{14}$. Y el otro aspecto tiene que ver con el placer. Se trata de crear belleza, de entender que incluso en el infierno hay algo que puede refutar los dolores y los quebrantos. En ese sentido, la literatura tiene un compromiso rebelde: procurar felicidad donde parecería que esta no tiene derecho a ocurrir (Seoane, 2021: 8-9).

Seoane (2021: 9) afirma que según Villoro «la realidad política depende de la construcción de narrativas» y que «defiende el papel del periodismo para hallar la verdad [...], y por encima de todo la novela» (2021: 10). En esta línea, expone Villoro:

Este artefacto es uno de los mecanismos más eficaces para entender la complejidad de todas estas narrativas que se cruzan en nuestro día a día. [...] Es un mecanismo para dar sentido, confrontar y amalgamar todo tipo de relatos, todas esas tramas y visiones de la realidad que, sueltas y por separado, tratan de imponer un pensamiento único. Unirlas y explicarlas es lo único que nos puede hacer pensar de forma crítica (Seoane, 2021: 10).

Juan Gabriel Vásquez escribe una nota final a su última novela (Volver la vista atrás) para tratar de explicar la aparente paradoja de que sea «una obra de ficción, pero no hay en ella episodios imaginarios» (2021: 473). Para ello comenta con agudeza el epígrafe que antepuso a la novela y que resuena aún en la mente del lector. Se trata de una cita de Ford Madox Ford que aparece en el prefacio de su Joseph Conrad. A Personal Remembrance. Vásquez (2021: 474) explica su sentido de esta manera:
El autor se dispone a contarnos la vida de un amigo, y su frase completa es ésta: «Pues, según nuestra visión de las cosas, una novela debería ser la biografía de un hombre o un caso, y toda biografía de un hombre o un caso debería ser una novela ${ }^{15}$, siendo ambas, si se ejecutan de manera eficiente, interpretaciones de tales casos como son las vidas humanas». Me gusta la idea de interpretación, pues eso es lo que me vi haciendo más de una vez con los hechos de la vida de Sergio Cabrera. Mi labor de novelista, frente al magma formidable de sus experiencias y las de su hermana, consistió en darles a esos episodios un orden que fueran más allá del recuento biográfico: un orden capaz de sugerir y revelar significados que

\footnotetext{
${ }^{14}$ En relación con esta idea de «orden», hablaba Umberto Eco de la «función terapéutica de la narrativa», también en este caso desde el punto de vista del lector y no solo del creador: «leer relatos significa hacer un juego a través del cual se aprende a dar sentido a la inmensidad de las cosas que han sucedido y suceden y sucederán en el mundo real. Al leer novelas, eludimos la angustia que nos atenaza cuando intentamos decir algo verdadero sobre el mundo real. Esta es la función terapéutica de la narrativa y la razón por la cual los hombres, desde los orígenes de la humanidad, cuentan historias. Que es, al fin, la función de los mitos: dar forma al desorden de la experiencia» (Eco, 1996: 96-97).

${ }^{15}$ Hasta aquí llegaba la cita de Ford Madox Ford que servía de epígrafe de Volver la vista atrás.
} 
no son visibles en el simple inventario de los hechos, porque pertenecen a formas distintas del conocimiento. No es otra cosa lo que hacen las novelas ${ }^{16}$.

\section{3.- NúÑEZ RAMOS Y EL PENSAMIENTO NARRATIVO}

Normalmente, un teórico de la literatura se sitúa ante estas mismas cuestiones con otra perspectiva y con otras herramientas. Por lo tanto, debe responder con diferente método y con formulaciones argumentadas desde un horizonte epistemológico también diferente, aunque, como podrá ver el lector, puedan observarse coincidencias o confluencias muy significativas en el modo último de comprender el fondo de la cuestión un teórico y un creador de ficciones. A mi entender, Rafael Núñez es un ejemplo sobresaliente de ese modo radical de situarse un teórico ante el problema de la función de la literatura en relación con el conocimiento poético y de los aspectos cognitivos del relato. ¿Cómo caracterizar su aproximación o su enfoque crítico? ¿cuáles son los puntos fundamentales de su teoría? ¿a qué conclusiones conduce su pensamiento? Me limitaré ahora a algunas observaciones principales al respecto, con citas significativas que espero que resulten sugerentes y animen al lector a realizar su propia lectura reposada y completa de El pensamiento narrativo. En ese sentido, dejaré hablar sobre todo a Núñez Ramos a través de sus propias palabras, pues ha llegado a una formulación extremadamente precisa de su pensamiento que no admite con facilidad el parafraseo ${ }^{17}$.

En el Preámbulo a su obra, parte Núñez Ramos de una idea paradójica y algo misteriosa, que aparece en el ámbito del arte y más concretamente de la literatura y que formula inicialmente así: «a través de un mensaje manifiestamente falso acerca de la realidad [...] la literatura nos conduce a numerosas verdades acerca de la existencia humana» (Núñez Ramos, 2010: 14) ${ }^{18}$. Pero para que esa «fulguración cognitiva» (2014: 57) se produzca tienen que ponerse en funcionamiento procesos mentales y cerebrales, mecanismos múltiples y muy

\footnotetext{
${ }^{16}$ La nota de Vásquez continúa así, hasta los agradecimientos: «A esto nos referimos, creo, cuando hablamos de imaginación moral: a esa lectura de una vida ajena que consiste en observar para conjeturar, o en penetrar lo que es manifiesto para descubrir lo oculto o lo secreto. La interpretación es también parte del arte de la ficción; que el personaje en cuestión sea real o inventado es, en la práctica, una distinción inconducente y superflua» (Vásquez, 2021: 475).

17 Véase, sin embargo, el valioso esfuerzo sintético de Pedro Alonso García, quien calificaba El pensamiento narrativo como «un ejercicio especulativo de exquisita factura y solidez argumentativa y de evidente originalidad en el panorama de la investigación teórico-literario de nuestro país» (Alonso García, 2011: 199).

${ }^{18}$ Es lo que Mario Vargas Llosa denominó con acierto «la verdad de las mentiras». Ver al respecto el primer ensayo de su libro con ese mismo título (Vargas Llosa, 1990: 13-28).
} 
complejos, activándose amplios dominios de conocimiento con estrechas relaciones entre ellos. Reconoce Núñez, entonces, que «la literatura es algo más que una forma para ser admirada» y «que apela a múltiples fibras del ser humano y le exige una profunda implicación», por lo que se entiende bien que conciba una teoría de la literatura que necesariamente tiene que «integrar conocimientos de las diversas disciplinas que estudian al hombre, desde la antropología a la psicología evolutiva, desde la sociología a la filosofía de la mente, desde la lingüística a la neurología» (2010: 14). No se queda sin más en una declaración de intenciones, porque uno de los aspectos relevantes de la teoría de Núñez Ramos es cómo se enriquecen su discurso y su argumentación con las aportaciones de estas disciplinas que de modo coherente explican o matizan las proposiciones más netamente teórico literarias, con el fin de ahondar en la concepción de «la literatura como forma de conducta expresiva del ser humano» (2010: 19). Las citas, entre otros, de Bateson, Damasio, Frith, Maturana, Storey, no son elementos adheridos, sino que, a través de su comentario, permiten desembocar, por ejemplo, en un apartado del capítulo 5 («La ficción como conocimiento») que se titula «Procesos cognitivos en la lectura de relatos literarios» o en un capítulo 6 que significativamente lleva por título «El sentimiento en la acción, la mente y el cerebro» ${ }^{19}$. El lector sale igualmente enriquecido al reconocer la variedad y complejidad de factores que intervienen en el proceso de lectura de textos narrativos, desde una perspectiva infrecuente que ahonda en la base antropológica de nuestra experiencia del arte narrativo.

La teoría de Núñez Ramos se apoya en dos puntos fundamentales que por sí mismos no son novedosos, pero que ganan en significación y son iluminados al considerarse desde este horizonte interdisciplinar. Por un lado, aunque la narración esté presente en otras

\footnotetext{
19 Aunque parezca muy largo, es imprescindible dar un ejemplo significativo de cómo Núñez Ramos integra en su perspectiva los hallazgos de otras disciplinas, reforzando de este modo el desarrollo de su argumentación: «Queda, pues, de manifiesto que la comprensión de la literatura tiene sus raíces y fundamento en el funcionamiento de nuestras mentes que, a su vez, puede relacionarse con la arquitectura cerebral. Los filósofos y psicólogos cognitivos y evolutivos nos facilitaron evidencias obtenidas por medio de múltiples experimentos en los que someten a pruebas a individuos de todo tipo: la conclusión de todas las teorías divergentes a veces en los datos y los argumentos, es que el ser humano posee algo así como una psicología popular o teoría de la mente que le incita desde muy pronto a leer la mente de los demás, a atribuir intenciones a las acciones de los otros, razón por la cual somos capaces de leer satisfactoriamente textos de ficción, porque no captamos en ellos simplemente su valor referencial, sino la vida afectiva o la cosmovisión que implican y que, en el curso de la lectura y de manera intuitiva, les atribuimos con toda naturalidad. Los neurólogos como Damasio [...] estudian con la tecnología moderna y en las patologías de ciertos individuos el funcionamiento del cerebro, las zonas que se activan en unas y otras circunstancias, la naturaleza de las patologías en relación con las zonas dañadas, y cuestiones similares. Estos estudios confirman la idea de un comportamiento narrativo y hasta literario del cerebro y de la mente [...]» (Núñez Ramos, 2010: 142).
} 
muchas facetas de la actividad humana ${ }^{20}$, se centra en el relato literario, y más precisamente en los «hechos ficticios, que no son [...] el significado de la obra, sino su significante fundamental» (Núñez Ramos, 2010: 116).

Nos interesa la representación narrativa de los hechos y las acciones, porque hechos y acciones constituyen el elemento específicamente narrativo que permanece en todas las manifestaciones y porque en ellos se encuentra el factor más importante de la comunicación artística, como ya destacaba Aristóteles [...] (Núñez Ramos 2010: 59).

Núñez Ramos, por lo tanto, no dedica su atención primera a ese tipo de relatos, híbridos entre narración y poesía, en los que «la palabra llama la atención por sí misma, por cómo se configura, por su función poética» (2010: 72) ${ }^{21}$. Como en ese tipo de relatos «los hechos no se transparentan tan fácilmente» insiste en que, para el propósito de su investigación, «el interés se encuentra en los elementos de la historia, es decir, en la sucesión de acciones y de acontecimientos encadenados que identifican al texto narrativo frente a los demás tipos de textos» (2010: 73).

El segundo punto fundamental tiene que ver con una concepción constructivista de la comunicación y del conocimiento, por lo que se subraya en todo momento la colaboración del lector en la construcción del sentido del relato, mediante una intervención creadora. Esta concepción se transparenta a lo largo de toda la obra de Núñez Ramos, pero se concreta de un modo muy claro en las páginas finales del último capítulo, en el apartado «Juicio estético y conocimiento narrativo», para tratar de conciliar algo que había sugerido unas páginas antes: el hecho de que «el resultado de la comunicación [sea] siempre específico de cada destinatario» pero que al mismo tiempo sea comunicable y pueda establecerse un consenso intersubjetivo, porque «están presentes factores de reciprocidad y reconocimiento que favorecen la comunicación plena en torno a contenidos no formulados» (2010: 168).

Frente a los textos plenos, argumentativos,

el lector de un relato literario no tiene significación que reconocer, pues lo que recibe, en principio, es información pura acerca de hechos concretos; corresponde por completo al lector construir su sentido en el acto de lectura y lo hace, estimulado por el texto, poniendo en juego todo su ser, actualizando todos

\footnotetext{
20 Precisa Núñez en una nota de la página 128 que «para los aspectos que estamos aquí tratando, la narración abarca a la casi totalidad de las formas de arte, en la medida en que expresan el sentimiento por medio de acciones humanas: teatro, cine, danza e incluso poesía».

${ }^{21}$ Pone como ejemplos Larva, de Julián Ríos, Palinuro de México, de Fernando del Paso, o La guaracha del macho Camacho, de Luis Rafael Sánchez.
} 
los niveles de conciencia. Por esta razón, el sentido es una formación compleja, unitaria pero rica en matices, solo en parte nocional, que ningún resumen, paráfrasis o interpretación del texto puede captar. [...]: la plétora de estímulos que contiene el texto y la pluralidad de dimensiones del hombre que se ponen en juego favorecen la diferenciación de las experiencias, mientras que la identidad textual y la comunidad biológica y social de los lectores generan el sentimiento íntimo de participación [...] (Núñez Ramos, 2010: 182).

Elpensamiento narrativo se estructura en dos partes bien articuladas. En la primera la investigación avanza por sus pasos con un gran rigor lógico en sus definiciones, desde la consideración de la literatura como $\operatorname{arte}^{22}$ y como forma de comunicación a la precisión de los conceptos y propiedades del «texto», en general, y del «texto narrativo» más específicamente, distinguiéndolo del «texto argumentativo». Tras este recorrido y antes de pasar a considerar propiamente la estructura del texto narrativo, Núñez Ramos (2010: 57) proporciona una segunda formulación a la pregunta central de su investigación:

El texto narrativo [...] se capta directa y abiertamente en los hechos representados, sin ser sin embargo la mera representación de los hechos. [...] Los hechos aparecen de tal manera que su mera contemplación (a través de la lectura en la narración literaria) ofrece a la mente que los contempla una sensación de plenitud, de sentido, de significación no nocional, de valoración emotiva no escindida de los hechos, sino como una especie de esplendor de los mismos. Creemos que aquí se encuentra la fascinación que producen los grandes relatos, que nos están transmitiendo mucho sentido sin que lo captemos como pensamiento abstracto, como representación mental consciente, explícita y conceptual. Parece algo mágico y paradójico. ¿Cómo podemos captar sentido sin una representación intelectual, sin una conciencia clara y distinta de su contenido, sin una superación y separación de la referencia ficticia? Nuestro principal propósito es responder a estas preguntas, dar una explicación rigurosa que dé sentido a expresiones aparentemente contradictorias como «conocimiento narrativo» $\mathrm{O}$ «pensamiento narrativo» ${ }^{23}$.

\footnotetext{
${ }^{22}$ En el pensamiento de Núñez Ramos, tal como ya se podía apreciar en La poesía, tiene un lugar especial la filosofía de Susanne K. Langer y su consideración del arte como «una expresión (proyección, forma simbólica) del sentimiento humano para su conocimiento y contemplación», definición que Núñez se detiene a analizar, comparándola con otras concepciones (2010: 21-30). Es imprescindible para entender correctamente formulaciones posteriores de Núñez, como cuando se refiere a «la expresión del sentimiento a través de las acciones fingidas» (2010: 95) o a que «la literatura es también una forma de conocimiento de la realidad y del sentimiento humano» (2010: 89). Otra aportación filosófica fundamental es la que procede de la teoría del arte como juego, símbolo y fiesta, formulada por Hans-Georg Gadamer en La actualidad de lo bello, aunque de un modo más evidente se aprecie en el libro de Núñez Ramos sobre La poesía.

${ }^{23}$ Es propio del modo de avanzar en su discurso que Núñez Ramos vuelva a reformular un pensamiento central tras haber proporcionado nuevos argumentos y puntos de vista, con lo que se gana un nuevo nivel de precisión. Casi veinte páginas más adelante, a modo de conclusión de la Parte primera, retoma por tercera vez esta cuestión fundamental de las dos condiciones aparentemente paradójicas en el conocimiento narrativo: «cómo una serie de proposiciones no verdaderas puede constituir auténtico conocimiento y, por tanto, transmitir una verdad»y «cómo la presentación de lo concreto puede proporcionar un conocimiento que trascienda la pura información sobre la ocurrencia de los eventos sin constituir contenido conceptual y abstracto» (2010: 173). Pruebas de este
} 
Y a este propósito dedica Núñez Ramos la segunda parte de su investigación, a través de tres capítulos que, desde su método interdisciplinar, desarrollan específicamente las cuestiones de «la ficción como conocimiento» (2010: 77-120), del «sentimiento en la acción, el medio y el cerebro» (2010: 121-152), y, por último, de «la comunicación, el texto narrativo y el juicio estético» (2010: 153-182).

Las diez páginas de las «Conclusiones» (Núñez Ramos, 2010: 185-194), introducidas por una bella cita de Tobias Wolf ${ }^{24}$, merecen lectura atenta, pues recogen en su densa y precisa concisión nuevas formulaciones con numerosas resonancias de lo leído en las páginas anteriores, al mismo tiempo que abren nuevas perspectivas de exploración. Para los efectos de este artículo, me interesa subrayar tres de las ideas sobre las que se articula el primer apartado de las conclusiones:

1) sin comprender las habilidades cognitivas del hombre, su capacidad para penetrar en las mentes de otros y relacionar sus hallazgos con las experiencias propias, no sería realizable la función nuclear de la literatura: la expresión y el conocimiento del sentir humano [...]. En el ejercicio de esta función nuclear las disposiciones cognitivas ponen en juego relaciones y contenidos que hacen de la literatura un complemento de la historia, pues refleja las condiciones sociales de su tiempo, y de la filosofía, pues habla del hombre en general, si bien ambas cosas en un lenguaje propio no conceptual (Núñez Ramos, 2010, 185);

2) es el lector el que tiene que construir el sentido del mensaje, un sentido que, en definitiva, no es sino la actitud, el sentimiento o la cosmovisión de otro u otros. La literatura nos hace comprender vidas ajenas, imaginar lo que significa ser otro ser humano distinto de nosotros, la experiencia de la otredad que, puesto que se elabora activando nuestras disposiciones y nuestras experiencias acumuladas y se confronta con ellas, acaba siendo también una toma de conciencia de nosotros mismos (Núñez Ramos, 2010, 187);

3) la literatura nos invita a penetrar en el mundo interior de los otros y, de esta manera, a participar y comprender sus motivaciones y actitudes; es este un valor ético nada desdeñable que surge del funcionamiento mismo de la comunicación artística, de la eficacia del texto para plasmar en la acción las fuerzas que mueven a los personajes. [...]. No se trata, pues, de la ejemplaridad moral de las conductas que se muestran para ser seguidas o evitadas, se trata de la ejemplaridad cognitiva por la cual comprendemos las conductas, aunque sean reprobables, porque conocemos los movimientos interiores que las rigen, movimientos que, según vimos, aun siendo específicos de cada relato, están fuertemente imbricados en la estructura

método son también las síntesis que coloca al final los capítulos 5 y 6 (2010: 116-120; 151-152), que orientan al lector en todo momento.

${ }^{24}$ «A mí la literatura me ha cambiado, me ha dado una profundidad de conciencia que no tenía, me ha ayudado a ver el mundo de otra manera, me ha agrandado el corazón. Tobias Wolf» (Núñez Ramos 2010: 185). 
social y evocan los que determinan otras conductas reales y posibles (Núñez

Ramos, 2010: 188) ${ }^{25}$.

\section{4.- CODA}

Simplemente por medio de los tres puntos que he elegido de entre sus conclusiones, puede intuirse de qué modo el pensamiento que Núñez Ramos desarrolla en este libro nos puede conducir a comprender mejor el sentido de la «ejemplaridad» de las Novelas ejemplares de Cervantes o el valor de escuchar cómo Lázaro de Tormes nos relata las fortunas y adversidades de su propia vida, o de tomar noticia de la conducta criminal del pobre y terrible Pascual Duarte, por referirme a obras que estoy acostumbrado a explicar en las aulas. Sin embargo, he notado que la huella de la lectura de Elpensamiento narrativo ha sido muy honda para mí en tiempos recientes y por otros motivos, al encontrar comprobación en mi propia experiencia como investigador, como traductor y como lector de textos narrativos complejos. La experiencia de co-traducir doce relatos de Akutagawa y de prepararlos para la edición con introducción y notas se llevó a cabo al mismo tiempo que el desarrollo de mi proyecto de investigación principal que me obligaba a leer cientos de documentos relacionados con los intentos de evangelización del Japón en el siglo XVI, durante los cuales se utilizó el teatro como medio de adoctrinamiento ${ }^{26}$. Los de Akutagawa son doce relatos, como los cervantinos, pero no publicados originalmente constituyendo un volumen al modo de las Novelas ejemplares. En ellos Akutagawa imagina numerosas vidas humanas en el contexto

\footnotetext{
${ }^{25}$ De «imaginación moral» hablaba más arriba una cita de Juan Gabriel Vásquez. Por este camino del valor ético o moral de la narrativa y del arte en general se mueve una corriente de pensamiento norteamericano que especialmente representa en nuestro tiempo Martha C. Nussbaum y que apunta al valor de la literatura y de las artes en la formación de ciudadanos responsables. Tal pensamiento lo desarrolla de modo ejemplar en su texto «La imaginación narrativa» (Nussbaum, 2005: 117-144), donde defiende con optimismo que «las artes cultivan las capacidades de juicio y sensibilidad que pueden y deben expresarse en las opciones de los ciudadanos» (2005: 118), añadiendo más adelante: «Si seguimos la idea de Whitman, concluiremos que es esencial proporcionar al estudio de la literatura un lugar central en un currículo para la construcción de la ciudadanía, ya que ella desarrolla las artes de la interpretación que son esenciales para la participación y la conciencia cívicas» (2005: 31). Este capítulo, que contiene también valiosa reflexión sobre la combinación de una «lectura empática» con una «lectura crítica» de los textos narrativos, coloca como epígrafe una luminosa cita del constitucionalista Alexander Meiklejohn: «Existen muchas formas de pensamiento y de expresión en la amplia gama de la comunicación humana de las cuales el votante deriva el conocimiento, la comprensión y la sensibilidad a los valores humanos: la capacidad de emitir un juicio sano y objetivo que, en lo posible, el voto debería expresar. [...] El pueblo necesita de las novelas y del teatro, de las pinturas y de los poemas, "porque será llamado a votar"» (Nussbaum, 2005: 117). [Modifico muy ligeramente la traducción e introduzco unos corchetes para atenerme mejor al original, «The First Amendment Is an Absolute», 1961].

${ }^{26}$ Le théatre et la rencontre des cultures ibérique et japonaise au $16^{6}$ siècle, proyecto financiado por el «Conseil de recherche en sciences humaines du Canada» (2016-2022).
} 
de la presencia de misioneros cristianos en el Japón de los siglos XVI y XVII. Son vidas de gente japonesa que entra en contacto con personas, ideas y costumbres que vienen de otro mundo muy lejano y que afectan de modo radical su existencia, pero principalmente son fragmentos de vidas de japoneses (cristianos o no) en su relación con los bateren (padres o sacerdotes) católicos. Quizás sea una ilusión o un espejismo, pero ningún otro libro de historia o de filosofía de los que estudian ese periodo me ha proporcionado una sensación similar de que comprendía algunas reacciones del pueblo japonés en su contacto con los occidentales $^{27}$. Precisamente son estos relatos los que me han posibilitado imaginar de un modo más eficaz la otredad, «la actitud, el sentimiento o la cosmovisión de otro u otros» (Núñez Ramos, 2010: 187). En este conjunto de relatos imaginarios no aparecen explícitamente opiniones o reflexiones en un lenguaje argumentativo que declaren posiciones ideológicas claras sobre el conflictivo encuentro de culturas occidental y japonesa: el estímulo para el lector proviene directamente de los hechos, lo que ocurre a los personajes y sus palabras tal como aparecen en sus vidas imaginadas, poniéndose en marcha los complejos procesos mentales movilizados en la lectura de textos narrativos, según explica Núñez Ramos.

Un ejemplo significativo permitirá ilustrar lo que quiero decir. En sus breves doce páginas, quizás el más simple e impactante de los relatos sea O-Shino (Akutagawa, 2021: 85-98). Cuenta el narrador que nos encontramos en el interior del templo cristiano de Kioto en el atardecer de un día nublado. Un sacerdote (bateren) de unos cuarenta y cinco años reza arrodillado en silencio. En el templo solitario entra una mujer con un kimono gastado; tiene un aspecto pálido y cansado, envejecido a pesar de no haber cumplido aún los cuarenta. Mira con curiosidad el interior del templo y espera en silencio a que el sacerdote acabe sus rezos. Luego, le saluda, y dice llamarse Shino y ser la viuda de un samurái que tiene un hijo gravemente enfermo, por lo que pregunta al sacerdote si puede examinar a su hijo. Está

\footnotetext{
${ }^{27}$ Nos preguntábamos los traductores en la introducción a la edición de los relatos «Desde el punto de vista cultural y religioso, podrían plantearse numerosas preguntas en torno al apasionante periodo histórico de la primera presencia europea en Japón, y del conflictivo encuentro entre Oriente y Occidente producido entonces. ¿Cómo entendieron los japoneses la nueva creencia que traían esos extraños extranjeros, bárbaros del sur (nanban)? ¿qué esperaban de ella? ¿Prendió verdaderamente la semilla del Evangelio en el corazón de los japoneses que se bautizaron? ¿Era posible un entendimiento entre el Dios de los europeos y los dioses nipones, o fue inevitable la confrontación? ¿Podría haber triunfado realmente la fe en los reinos del Japón, tierra donde se cruzaban con el mundo numinoso sintoísta, la ética confuciana y el pensamiento budista? ¿No estaría este encuentro lleno de malentendidos culturales insuperables? ¿Dejó alguna huella todo este episodio que terminó en un baño sangriento de mártires? Por su parte el modo de enfocar Akutagawa las respuestas a preguntas de este tipo es el modo de un creador de ficciones que con su imaginación propone una diversidad de mundos y de vidas posibles, que nos sorprenden por la variedad de perspectivas que ofrecen y por los giros inesperados de la narración. No es la respuesta de un filósofo ni la de un historiador, sino una respuesta irónica que, de manera más o menos consciente, sigue la senda abierta por Miguel de Cervantes trescientos años antes» (Higashitani y Rubiera 2021: 20)
} 
preocupada, pero todo lo dice sin expresión en el gesto, como si llevara una máscara. Mira al sacerdote extranjero, pero sin implorarle. El sacerdote reflexiona, pues la mujer viene a pedirle por la curación del cuerpo de su hijo, no por su alma, aunque una cosa podría llevar a la otra, así que accede a la petición de ayuda. Por fin, un brillo en los ojos de la mujer, que le da las gracias, conmueve al sacerdote al ver en aquella viuda la imagen de cualquier madre doliente, como la Virgen María misma. El sacerdote le dice que se tranquilice, que él conoce esas enfermedades y que, en todo caso, que si no solucionaran nada los medios humanos... Pero en ese momento la mujer le interrumpe y le dice que no se preocupe, que si eso no funciona que entonces irá a un templo budista a pedir protección a uno de sus dioses. Para asombro de la mujer, el sacerdote se enfada, recriminándole su actitud y diciéndole que se deje de esos dioses budistas y sintoístas que no son más que ídolos de madera y piedra: el único verdadero es el Dios de los cristianos, al que muestra en la vidriera del templo. Comienza entonces el sacerdote un encendido discurso en el que repasa algunos acontecimientos de la vida de Jesús desde su nacimiento hasta su muerte, y cuando llega al momento más emocionante en que declara cómo murió crucificado entre dos ladrones con sus palabras de triste lamento, nota la repentina contrariedad de la mujer, que comienza a mirarle con desprecio y le dice que ya ve que su «verdadero dios $[. .$.$] pertenece a esa clase de$ hombres» (Akutagawa, 2021: 96). Cambia de actitud, muestra firmeza y se dirige entonces al bateren con determinación y mucha dignidad: cuenta cómo su marido samurái nunca había retrocedido frente al ataque enemigo y relata algunos episodios en los que mostró siempre valentía, hasta el momento mismo de su muerte en combate... pero ese dios cristiano, qué caso más lamentable, qué vergüenza que se quejara de ese modo en la cruz, qué despreciable actitud: «¿Qué mérito podría tener la religión que adora a un cobarde como ese? Y a usted, que sigue la misma corriente de ideas dadas por ese cobarde, yo no puedo dejarle que examine la enfermedad de mi hijo por el respeto que debo [...] a mi marido fallecido» (Akutagawa, 2021: 97-98). Piensa ella que incluso su hijo enfermo se abriría el vientre antes que verse obligado a tomar medicinas de un cobarde como el bateren, y que ahora lo único que siente es rabia por haberse molestado en ir a ese templo.

El narrador solo hace este comentario para cerrar su relato: 
La mujer contuvo las lágrimas y, tan pronto como volvió la espalda al sacerdote con decisión, salió presta del templo como si huyera de un aire envenenado. Y dejó allí al sacerdote estupefacto... (Akutagawa, 2021: 98) ${ }^{28}$.

Aunque sea un simple e insuficiente resumen de los hechos, y no se hayan leído en la lengua original del texto, este relato me parece un ejemplo claro de cómo la ficción narrativa puede funcionar como complemento de la historia y de la filosofía —enriqueciendo nuestras experiencias, modificando nuestra conciencia y nuestra sensibilidad-y de cómo

los hechos aparecen de tal manera que su mera contemplación (a través de la lectura en la narración literaria) ofrece a la mente que los contempla una sensación de plenitud, de sentido, de significación no nocional ${ }^{29}$, de valoración emotiva no escindida de los hechos, sino como una especie de esplendor de los mismos (Núñez Ramos 2010: 57).

\footnotetext{
${ }^{28}$ Nótese que el relato ha de leerse, además, en el conjunto de los otros once. «La "realidad" que construye Akutagawa con estos doce relatos es compleja y en ella se cruzan encontrados puntos de vista sin llegar a una síntesis, que en último término solo puede resolver el receptor individual si lo cree necesario. La realidad de la ficción nos plantea seductoramente nuevas preguntas. ¿Es el mártir un héroe o un tonto? ¿ $\mathrm{O}$ es un héroe y un tonto a la vez? ¿Triunfa el diablo o es burlado al provocar que venza el Amor sin saberlo? [...] En el fondo, ¿en qué cree verdaderamente esa madre angustiada que solo quiere salvar la vida de su hijo o de su hija mortalmente enfermos? Y ese Kirisuto que se dejó morir en una cruz, ¿no tuvo el comportamiento de un cobarde, indigno del respeto de los honorables japoneses? Entre el asombro y la reflexión, "tú, lector, pues eres prudente, juzga lo que te pareciere"» (Higashitani y Rubiera, 2021: 20-21).

${ }^{29}$ Lo cual no quiere decir que no sea susceptible de conceptualizarse o de formularse por medio de proposiciones lógicas. Dice Núñez Ramos: «No es en absoluto desdeñable el esfuerzo intelectual que exige intentar formular en términos precisos la significación abstracta de los textos literarios: nos permite reconocer consciente y lúcidamente la profundidad que intuimos en los hechos y su trascendencia oculta, referirnos a ellos de forma económica y ágil, estudiarlos y ponerlos en relación con otras concepciones y fenómenos culturales. Sin embargo, su carácter conceptual, analítico y hasta reflexivo se opone radicalmente a la forma intuitiva, sintética, sensorial y emotiva propias de la percepción estética, otra forma de conocimiento que supone una mayor implicación personal en lo conocido a costa de la representación nocional» (Núñez Ramos, 2010: 57).
} 


\section{BIBLIOGRAFÍA}

Aguiar e Silva, Vítor Manuel (1981): Teoría de la literatura, versión española de Valentín García Yebra, Madrid Gredos.

Akutagawa, Ryūnosuke (2021): El tabaco y el diablo, y otros relatos cristianos, introducción, traducción y notas de Hidehito Higashitani y Javier Rubiera, Gijón, Satori.

Alonso García, Pedro (2011): «Revista de libros: El pensamiento narrativo. Aspectos cognitivos del relato, de Rafael Núñez Ramos. Oviedo, Servicio de publicaciones de la Universidad de Oviedo, 2010, 202 pp.», en Teorema, XXX, 2: 197-199.

Álvarez Moreno, Raúl (2021): «The Role of the Humanities During Times of Crisis», en https://fhis.ubc.ca/news/the-role-of-the-humanities-during-times-ofcrisis $/$ ?utm_medium=email\&utm_campaign=2021_03_InsideArts-Facultyand\&utm_source=Envoke-2021_0311_Faculty_Insid\&utm_term=Inside-Arts\%7C-Read-a-message-f (ultimo acceso: 5/11/21).

Bobes Naves, María del Carmen: «Los objetos y los modos de la investigación lingüística y literaria. La transversalidad», en Javier García Rodríguez (ed.) (2020): 279-297.

Cercas, Javier (2021): «¿Para qué sirve el sexo?», en El País Semanal, 29/09/2021: 74.

Eco, Umberto (1996): Seis paseos por los bosques narrativos, traducción de Helena Lozano Miralles, Barcelona, Lumen.

Fahmi, Mustapha (2020): «De quoi avons-nous besoin?», en Le Devoir, 24/12/20: B11.

Gadamer, Hans-Georg (1991): La actualidad de lo bello. El arte como juego, símbolo y fiesta, traducción de Antonio Gómez Ramos, Barcelona, Paidós.

García Rodríguez, Javier (ed.) (2020): Intersecciones. Relaciones de la Literatura y la Teoría, Oviedo, Ediciones de la Universidad de Oviedo.

Garrido Gallardo, Miguel Ángel; Emilio Frechilla Díaz (eds.) (2007): Teoría/Crítica. Homenaje a la profesora Carmen Bobes Naves, Madrid, CSIC.

Higashitani, Hidehito; Javier Rubiera (2021): «Introducción» en Akutagawa (2021): 11-21.

Langer, Susanne K. (1967). Sentimiento y forma. Una teoría del arte desarrollada a partir de una «Nueva clave de la filosofía», traducción de Mario Cárdenas y Luis Octavio Hernández, México, Centro de Estudios Filosóficos-UNAM.

Meiklejohn, Alexander (1961): «The First Amendment Is an Absolute», en The Supreme Court Review, 1961: 245-266. 
Núñez Ramos, Rafael (1992): La poesía, Madrid, Síntesis.

Núñez Ramos, Rafael (2010): El pensamiento narrativo. Aspectos cognitivos del relato, Oviedo, Universidad de Oviedo.

Nussbaum, Martha C. (2005): El cultivo de la humanidad. Una defensa clásica de la reforma en la educación liberal, traducción de Juana Pailaya, Barcelona, Paidós.

Ordine, Nuccio (2013): La utilidad de lo inútil. Manifiesto. Con un ensayo de Abraham Flexner, versión del italiano y el inglés de Jordi Bayod, Barcelona, Acantilado.

Seoane, Andrés (2021): «Juan Villoro: "Solo en los países sin lectores los escritores son considerados profetas"》, en El Cultural, 12-18 de noviembre de 2021: 8-10.

Shakespeare, William (1980): Macbeth. El rey Lear, traducción de Luis Astrana Marín, Barcelona, Bruguera.

Sidney, Sir Philip (2003): Defensa de la poesía, edición y traducción de Berta Cano Echevarría, $\mathrm{M}^{\mathrm{a}}$ Eugenia Perojo Arronte y Ana Sáez Hidalgo, Madrid, Cátedra.

Vargas Llosa, Mario (1990): La verdad de las mentiras. Ensayos sobre la novela moderna, Barcelona, Círculo de Lectores.

Vásquez, Juan Gabriel (2021): Volver la vista atrás, Barcelona, Alfaguara.

Wellek, René; Austin Warren (1966): Teoría literaria, versión española de José Ma Gimeno, Madrid, Gredos. 


\section{an}

U'e Actio nova: REVISTA DE TEORÍA DE LA LITERATURA Y LITERATURA COMPARADA, 5: 436-457 DOI: https://doi.org/10.15366/actionova2021.5.018

SOBRE EL AUTOR

\section{Javier Rubiera}

Professeur titulaire de Université de Montréal (Département de littératures et langues du monde).

ORCID: 0000-0002-0273-7116

Contact information: javier.rubiera@umontreal.ca 